\title{
Effect of Pulmonary Rehabilitation on Erector Spinae Muscles in Individuals With COPD
}

\author{
Yuji Higashimoto, Masashi Shiraishi, Ryuji Sugiya, Hiroki Mizusawa, Osamu Nishiyama, \\ Yamazaki Ryo, Takashi Iwanaga, Yasutaka Chiba, Yuji Tohda, and Kanji Fukuda
}

\begin{abstract}
BACKGROUND: A recent paper reported that low muscle mass in the erector spinae muscles (ESM) was strongly associated with poor prognosis and declining muscle mass over time in subjects with COPD. However, effects of pulmonary rehabilitation (PR), if any, on ESM mass have not been reported. We hypothesized that PR reduces the annual decline in ESM mass. METHODS: This was a retrospective cohort study. Thirty-nine subjects with COPD who received PR and underwent chest computed tomography before and after PR were evaluated (rehabilitation group). We also evaluated 39 age-matched subjects with COPD who did not receive PR (nonrehabilitation group). Data were collected from August 2010 until March 2020 in both groups. The ESM cross-sectional area $\left(\mathbf{E S M}_{\mathrm{CSA}}\right)$ was measured using axial computed tomography images, and annual changes were calculated. The 6-min walk distance (6MWD) was measured before and after PR; the minimum clinically important difference was defined as $30 \mathrm{~m}$. RESULTS: ESM $_{\text {CSA }}$ declined in the nonrehabilitation group over time $\left(-116.0 \pm 141.2 \mathrm{~mm}^{2} / \mathrm{y}\right)$ but increased in the PR group $\left(51.0 \pm 95.3 \mathrm{~mm}^{2} / \mathbf{y} ; P<.001\right)$. The annual increase in $\mathrm{ESM}_{\mathrm{CSA}}$ was significantly higher among subjects with an increase in 6MWD that exceeded the minimum clinically important difference compared with nonresponders in the rehabilitation group. The annual change in ESM $_{\text {CSA }}$ was negatively correlated with comorbidity index, and triple therapy (long-acting $\beta_{2}$ agonist/long-acting muscarinic antagonist/inhaled corticosteroid) had a favorable effect on annual change in ESM $_{\text {CSA }}$. Multiple regression analysis revealed that only PR was an independent

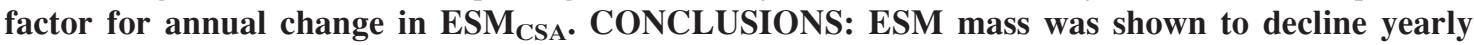
in subjects with COPD. The annual decline in muscle mass was reduced by PR. Key words: COPD; rehabilitation; skeletal muscle; computed tomography; rehabilitation outcome. [Respir Care 2021;66(9):1458-1468. (C) 2021 Daedalus Enterprises]
\end{abstract}

\section{Introduction}

Skeletal muscle dysfunction and atrophy are key systemic consequences of COPD and have important clinical implications, such as reduced exercise tolerance, quality of life, and even survival. ${ }^{1}$ Sarcopenia describes age-related loss of skeletal muscle. The prevalence of sarcopenia is $14.5-24 \%$ in patients with COPD and increases with age and disease severity. ${ }^{2,3}$ Although body mass index (BMI) is indicative of basic nutritional status and has been reported to predict mortality in subjects with $\mathrm{COPD},{ }^{4} \mathrm{BMI}$ is not sensitive to changes in body composition as it can be normal or even increased despite the occurrence of muscle wasting., McDonald et $\mathrm{al}^{7}$ reported that the pectoralis muscle area was more significantly associated with COPD-related traits, including pulmonary function, dyspnea sensation, and exercise capacity, compared with BMI using existing computed tomography $(\mathrm{CT})$ scans in a previous epidemiologic study. The pectoralis muscle is an accessory respiratory muscle that contributes to inspiration, ${ }^{8}$ and the cross-sectional area (CSA) of muscles is correlated with pulmonary function parameters, such as $\mathrm{FEV}_{1}$ and $\mathrm{FVC}^{7}$ Tanimura et $\mathrm{al}^{9}$ reported that the CSA of the mass of the erector spinae muscles $\left(\mathrm{ESM}_{\mathrm{CSA}}\right)$ is the strongest risk factor for mortality compared with other clinical parameters including lung function, $\mathrm{P}_{\mathrm{a}} \mathrm{O}_{2}$, BMI, modified Medical Research Council (mMRC) dyspnea scale, comorbidity indexes, St George Respiratory Questionnaire score, prior COPD exacerbations, and smoking history in subjects with COPD. These investigators also reported that $\mathrm{ESM}_{\mathrm{CSA}}$ decreased yearly in subjects with 
COPD. ${ }^{10}$ Because the trunk muscles, including ESM, have an important role in stabilizing the body, maintaining posture, and controlling spinal and pelvic movement, atrophy of these muscles may lead to an increase in the risk of falling and disability in activities of daily living in elderly people and patients with COPD. ${ }^{11,12}$

Both pectoralis muscles and ESMs can be assessed with chest $\mathrm{CT}$. Because chest $\mathrm{CT}$ is usually performed to diagnose and evaluate emphysema and to exclude other critical pulmonary diseases, such as lung cancer and pulmonary fibrosis, these images may simultaneously be used to evaluate local skeletal muscle mass without a need for additional radiation exposure.

A previous study reported that pulmonary rehabilitation (PR) enhanced lower limb muscle function and increased muscle mass ${ }^{13}$; however, the effect of PR on ESMs or pectoralis muscles has not been evaluated. We hypothesized that PR increases muscle mass for both ESM and pectoralis muscles and reduces the annual decline in muscle mass.

\section{Methods}

\section{Subjects and Study Design}

This was a retrospective cohort study. The Ethics Committee of Kindai University approved this study (approval number, R02-012) and authorized a waiver of consent. Confidentiality of subject information was guaranteed. The study was conducted in accordance with the Declaration of Helsinki. The basic information in this study has been registered with the University Hospital Medical Information Network Clinical Trials Registry (UMIN 00042233).

Medical records were reviewed to evaluate the effect of PR on ESM mass in subjects with COPD. A total of 89 subjects (age range, 51-91 y) with COPD were referred to the

Dr Higashimoto, Mr Shiraishi, Mr Sugiya, Mr Mizusawa, and Dr Fukuda are affiliated with the Department of Rehabilitation Medicine, Kindai University School of Medicine, Osaka, Japan. Drs Nishiyama, Ryo, and Iwanaga are affiliated with the Department of Respiratory Medicine and Allergology, Kindai University School of Medicine, Osaka, Japan. Dr Chiba is affiliated with the Division of Biostatistics, Clinical Research Center, Kindai University School of Medicine, Osaka, Japan.

Supplementary material related to this paper is available at http://www. rcjournal.com.

Dr Tohda has disclosed relationships with Kyorin Pharmaceutical, Teijin Pharma, Meiji Seika Pharma, Boehringer Ingelheim, Daiichi Sankyo, Astellas Pharma, and Pearl Therapeutics. The other authors have disclosed no conflicts of interest.

Correspondence: Yuji Higashimoto MD PhD, 377-2 Onohigashi, 5898511, Osakasayama, Japan. E-mail: yhigashi@med.kindai.ac.jp.

DOI: $10.4187 /$ respcare. 08678

\section{QUICK LOOK}

\section{Current knowledge}

Skeletal muscle dysfunction and atrophy are key systemic consequences of COPD and have important clinical implications, such as reduced exercise tolerance, quality of life, and survival. Erector spinae muscle (ESM) mass is the strongest risk factor for mortality and decreases year by year.

\section{What this paper contributes to our knowledge}

We used computed tomography to evaluate the effect of pulmonary rehabilitation (PR) on the annual change of ESM mass in subjects with COPD. ESM cross-sectional areas declined in subjects who did not receive PR and increased in subjects who received PR. Our results indicate that PR can effectively improve ESM in subjects with COPD.

out-patient PR program at Kindai University Hospital (Osaka, Japan) from August 2010 until March 2020. Seventy-one subjects completed the PR program (Fig. 1). Subjects were considered to have completed the program if they attended at least 12 sessions, given that most professional society guidelines recommend a minimum of 12 supervised sessions. ${ }^{14,15}$ Among the 71 subjects, 41 had 2 CT scans (before and after the PR program). Chest CT scans were performed at the physician's discretion to evaluate emphysema or to exclude the possibility of lung cancer, irrespective of this study. Therefore, a CT scan was not performed routinely in PR program attendees, and the interval between CT scans varied because of the retrospective nature of this observational study. Two subjects were excluded from the analysis because the $\mathrm{CT}$ scans were performed at the time of admission during a COPD exacerbation. A previous study reported that ESMs are affected by such exacerbations. ${ }^{10}$ Therefore, 39 subjects who completed the PR program were evaluated in this study (rehabilitation group). We also evaluated 39 age-matched out-patients with COPD who did not participate in the PR program and had 2 CT scans (non-rehabilitation group). All subjects in both groups were diagnosed with COPD and treated in the Department of Respiratory Medicine and Allergology of Kindai University Hospital. The diagnosis and classification of COPD were made according to the Global Initiative for Chronic Obstructive Lung Disease (GOLD) guidelines. ${ }^{16}$

The out-patient PR program was conducted twice a week for 12 weeks (24 sessions), and the PR maintenance program consisted of supervised endurance training once or twice per month. Each session consisted of respiratory muscle stretch gymnastics, ${ }^{17}$ followed by endurance training involving the lower limbs through exercise on a treadmill 


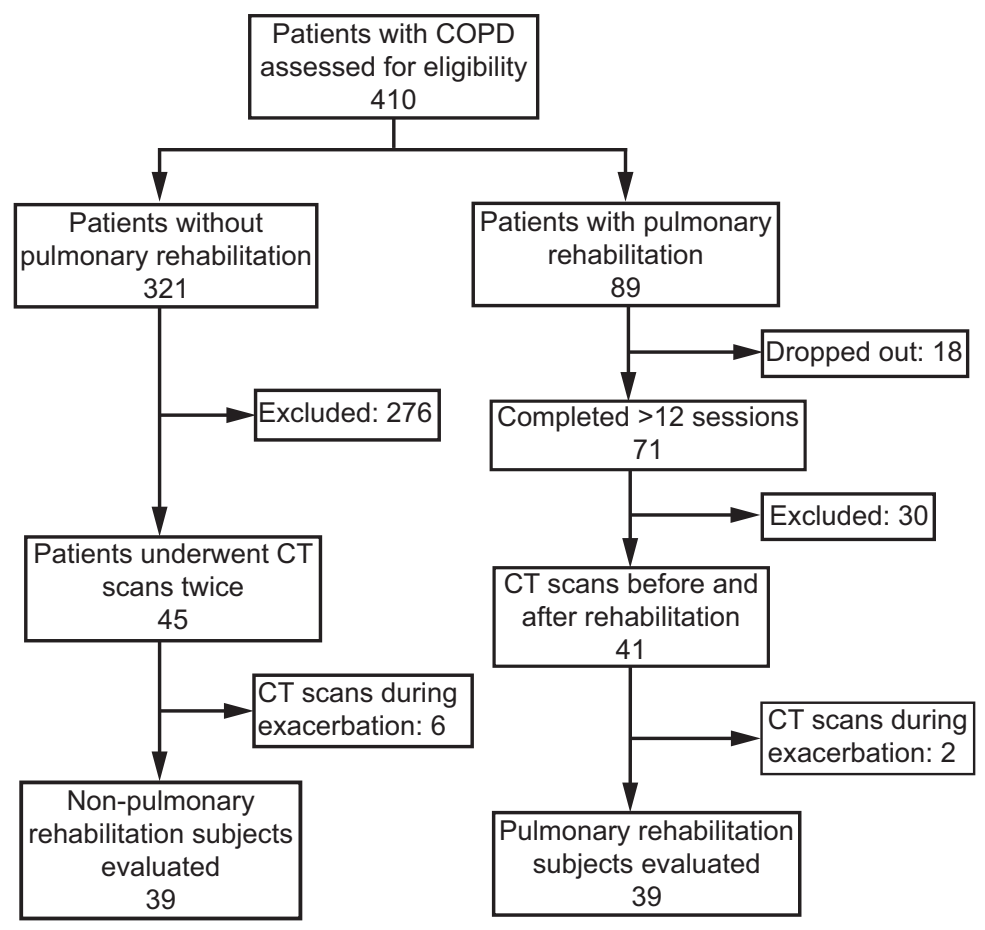

Fig. 1. Flow chart. $\mathrm{CT}=$ computed tomography.

or ergometric bicycling at $60-70 \%$ of peak work load for 20-40 min, and strength training of the upper and lower limbs for 10-20 min, as previously described in previous study. ${ }^{14}$ Respiratory muscle stretch gymnastics is designed to decrease chest wall stiffness, particularly of the respiratory muscles, because the majority of subjects with COPD had reduced chest wall mobility. ${ }^{17,18}$

\section{Clinical Variables}

Clinical data were retrieved from the medical files and included pulmonary function, current medications, smoking history, medical history, past COPD exacerbations, and comorbidities. Comorbidity indices (Charlson comorbidity index and COPD-specific comorbidity test) were calculated, as reported previously. ${ }^{14,19,20}$ We monitored severe exacerbations requiring hospitalization. All patients included in the study underwent spirometry (CHEST AC-55V; Chest, Tokyo, Japan), according to the method described in the American Thoracic Society guidelines. ${ }^{21}$ The single-breath diffusing capacity of the lung for carbon monoxide $\left(\mathrm{D}_{\mathrm{LCO}}\right)$ was also measured. ${ }^{22}$ The values for total lung capacity, FVC, residual volume, $\mathrm{FEV}_{1}$, and $\mathrm{D}_{\mathrm{LCO}}$ were related to the percentage of the predicted values. ${ }^{23,24}$ Exercise tolerance was assessed before and after the PR program by measuring the 6-min walk distance (6MWD) in accordance with the American Thoracic Society guidelines. ${ }^{25}$ The 6MWD was measured in the rehabilitation group, but not in the non-rehabilitation group. The minimum clinically important difference in the 6MWD was defined as an increase $>30 \mathrm{~m}^{26}$ Responders to pulmonary rehabilitation for exercise capacity were defined as having a 30-m increase in the 6MWD.

\section{CT Scan Acquisition and Analysis}

$\mathrm{ESM}_{\mathrm{CSA}}$ was measured using axial chest CT images at the level of the lower margin of the 12th thoracic vertebra with a manually drawn line depicting the $\mathrm{ESM}_{\mathrm{CSA}} \cdot{ }^{9,10,27} \mathrm{ESM}_{\mathrm{CSA}}$ is presented as the sum of the bilateral sectional areas calculated using the medical imaging and information management system (SYNAPSE 4.4.3, Fujifilm Medical, Tokyo, Japan; see the supplementary materials at http://www. rcjournal.com). ${ }^{9,10,27}$ The CSA of the pectoralis muscle $\left(\mathrm{PM}_{\mathrm{CSA}}\right)$ was also determined based on a single axial CT scan slice above the aortic arch, as described previously ${ }^{7,9}$ (see the supplementary materials at http://www.rcjournal. com). Emphysema was quantified by calculating the percentage of the low-attenuation area, determined using a cutoff value of $-950 \mathrm{HU}$ on whole-lung CT images using Synapse Vincent (Fujifilm Medical). ${ }^{9}$ Annual changes in the CSA of muscles were calculated from 2 CT scans using the following formula: (CSA in second CT scan - CSA in first CT scan)/(interval between two CT scans [in years]).

\section{Statistical Analysis}

Descriptive statistics were calculated for continuous variables, as represented by mean $\pm \mathrm{SD}$ (assumed to follow a 
normal distribution), median (interquartile range [IQR]; assumed to follow a non-normal distribution), and categorical variables by $n(\%)$. To compare 2 groups for parameters, we used the Student $t$ test (for continuous variables with normal distributions), the Wilcoxon rank-sum test (for nonnormal distributions), and the chi-square test (for categorical variables). The Shapiro-Wilk test was used to determine whether the distribution was normal. For comparison of the annual change of muscle CSA between groups (with vs without PR; responders vs non-responders), we performed linear regression using study groups and baseline values as explanatory variables. Correlations between parameters were assessed using Spearman's correlation analysis. Correlation coefficients $<0.4$ were considered to be weak, and those from 0.4 to 0.69 were considered to be moderate. ${ }^{28} \mathrm{We}$ also used standard least squares fitting with the restricted maximum likelihood method for multiple regression analyses. Comparisons between COPD stages or mMRC dyspnea scales were performed using analysis of variance. The minimum clinically important difference for 6MWD was defined as an increase $>30 \mathrm{~m} .^{26}$ Analyses were performed using JMP 11.2.0 software (SAS Institute, Tokyo, Japan).

\section{Results}

\section{Subject Characteristics}

There were no significant differences between the rehabilitation and nonrehabilitation groups with respect to age, gender, BMI, smoking history, percent of predicted FEV ${ }_{1}$, percent of predicted FVC, and drug treatment (Table 1). However, the rehabilitation group had more severe dyspnea (per the mMRC), more advanced GOLD stage, a greater proportion requiring long-term oxygen therapy, and more frequent exacerbations, while the nonrehabilitation group had a greater prevalence of asthma-COPD overlap and higher comorbidity indices (ie, Charlson comorbidity index). The proportion of prescriptions for inhaled drugs did not differ between the groups. With the exception of 1 subject in the nonrehabilitation group, the subjects were treated with a long-acting $\beta_{2}$ agonist (LABA) or a longacting muscarinic antagonist (LAMA). The interval between the first and second CT scans did not differ between the groups (rehabilitation group $2.3 \pm 1.3 \mathrm{y}$ vs nonrehabilitation group $2.1 \pm 1.2 \mathrm{y} ; P=.24)$. In the PR group, the interval between the first $\mathrm{CT}$ and the start of PR was $1.4 \pm 1.0 \mathrm{y}$, and between the end of PR and the second CT the interval was $0.9 \pm 0.7 \mathrm{y}$.

\section{Effect of PR on Annual Changes in Muscle CSA}

There were no significant differences between the rehabilitation and nonrehabilitation groups with respect to the mean values of $\mathrm{ESM}_{\mathrm{CSA}}$ or $\mathrm{PM}_{\mathrm{CSA}}$ at the time of the first or second CT scan (Table 1). ESM $\mathrm{CSA}_{\mathrm{CA}}$ decreased in 13 subjects in the rehabilitation group and in 33 subjects in the nonrehabilitation group. The annual changes in $\mathrm{ESM}_{\mathrm{CSA}}$ and $\mathrm{PM}_{\mathrm{CSA}}$ of the rehabilitation group (51.0 \pm 95.3 and $15.3 \pm 171.9 \mathrm{~mm}^{2} / \mathrm{y}$, respectively) were significantly higher than the changes in $\mathrm{ESM}_{\mathrm{CSA}}$ and $\mathrm{PM}_{\mathrm{CSA}}$ of the nonrehabilitation group $\left(-116.0 \pm 141.2 \mathrm{~mm}^{2} / \mathrm{y}, P<.001\right.$; and $-138.4 \pm 317.4 \mathrm{~mm}^{2} / \mathrm{y}, P=.02$, compared with the rehabilitation group) (Fig. 2, Table 2). We could not measure $\mathrm{PM}_{\mathrm{CSA}}$ in 2 subjects during the second $\mathrm{CT}$ scan because it was an abdominal CT scan. The annual changes in $\mathrm{ESM}_{\mathrm{CSA}}$ were significantly greater in subjects for whom the 6MWD increased more than the minimum clinically important difference (responders) $(n=17)$ compared with the other subjects $(n=22)$ in the rehabilitation group (responders $94.0 \pm 88.0$ vs nonresponders $17.0 \pm 88.4 \mathrm{~mm}^{2} / \mathrm{y}$, $P<.001$ ) (Fig. 3; see the supplementary materials at http:// www.rcjournal.com). The annual changes in $\mathrm{PM}_{\mathrm{CSA}}$ were not different between responders and nonresponders (responders $52.1 \pm 206.4$ vs nonresponders $-15.9 \pm 133.7$ $\mathrm{mm}^{2} / \mathrm{y}, P=.18$ ). There was no significant difference between responders and nonresponders in terms of background characteristics (see the supplementary materials at http://www.rcjournal.com).

\section{Effect of Clinical Background on Annual Changes in Muscle CSA}

The annual changes in $\mathrm{ESM}_{\mathrm{CSA}}$ or $\mathrm{PM}_{\mathrm{CSA}}$ were not affected by treatment with inhaled corticosteroids (ICS) $(P=.26$ and .28 , respectively; see the supplementary materials at http://www.rcjournal.com). The annual changes in $\mathrm{ESM}_{\mathrm{CSA}}$ were significantly greater in the 29 subjects who received triple therapy (LABA/LAMA/ICS) compared with the 49 subjects who did not $(23.6 \pm 131.8$ vs $-66.4 \pm$ $145.2 \mathrm{~mm}^{2} / \mathrm{y}$, respectively; $P<.001$ ). The median (IQR) of past COPD exacerbations was greater in subjects treated with triple therapy compared with other therapies, but this difference was not statistically significant (0 [IQR $0-2]$ vs 0 [IQR $0-1]$, respectively; $P=.22$ ), and a higher percentage of subjects with asthma-COPD overlap were treated with triple therapy $(62.1 \%)$ compared with other therapies $(16.3 \%)(P<.001)$. The annual changes in $\mathrm{PM}_{\mathrm{CSA}}$ were unaffected by triple therapy $(P=.26)$. When combined with asthma (ie, asthma-COPD overlap), the annual changes in $\mathrm{ESM}_{\mathrm{CSA}}$ or $\mathrm{PM}_{\mathrm{CSA}}$ were unaffected $(P=.81$ and .21 , respectively). Likewise, annual changes in $\mathrm{ESM}_{\mathrm{CSA}}$ or $\mathrm{PM}_{\mathrm{CSA}}$ were unaffected by long-term oxygen therapy $(P=$ .82 and .40 , respectively), nor were they different as a function of the GOLD stage ( $P=.82$ and .40 , respectively) or mMRC dyspnea scale ( $P=.12$ and .68 , respectively) (see the supplementary materials at http://www.rcjournal.com). 


\section{Pulmonary Rehabilitation and ERector Spinae Muscles}

Table 1. Subject Characteristics

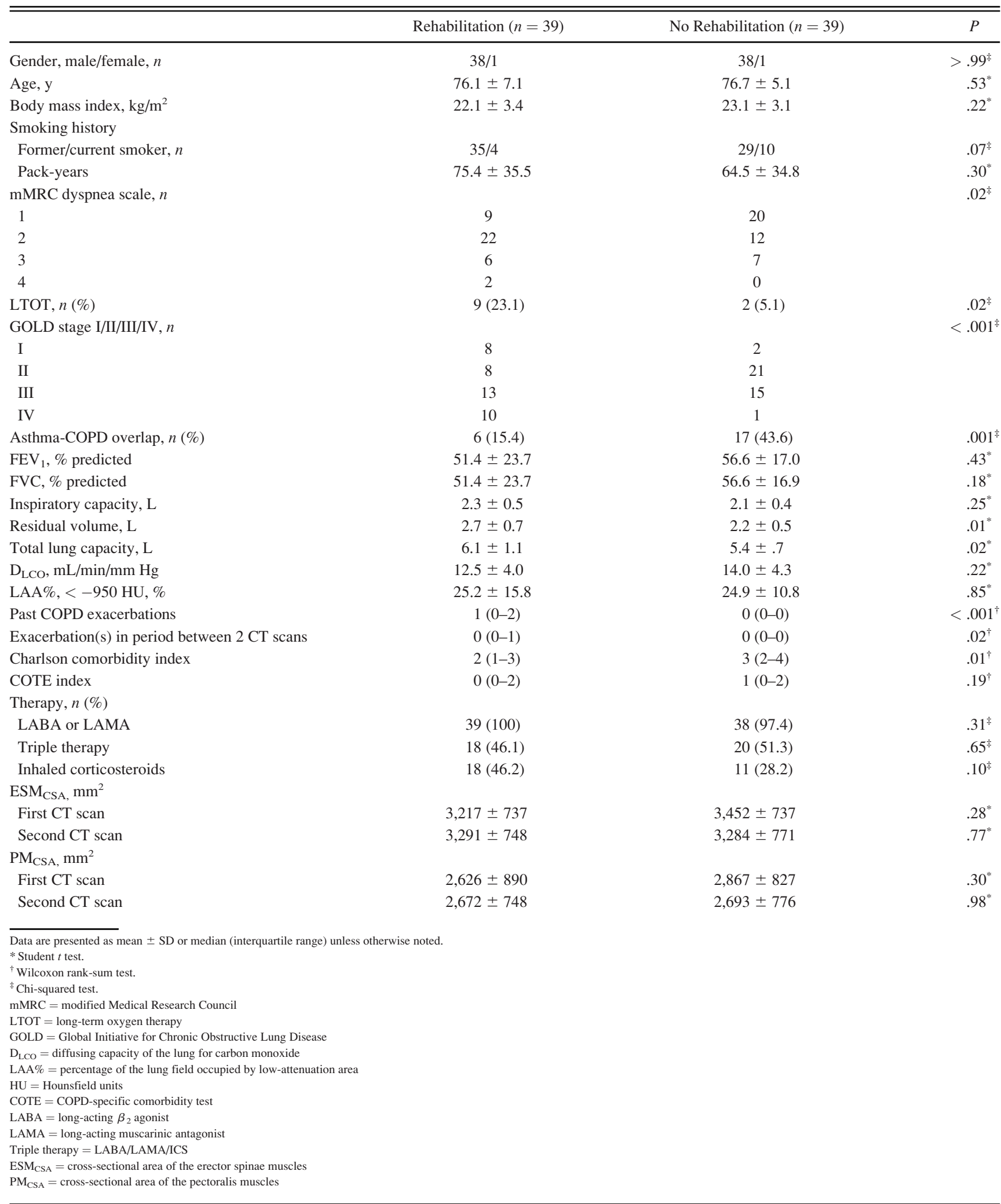



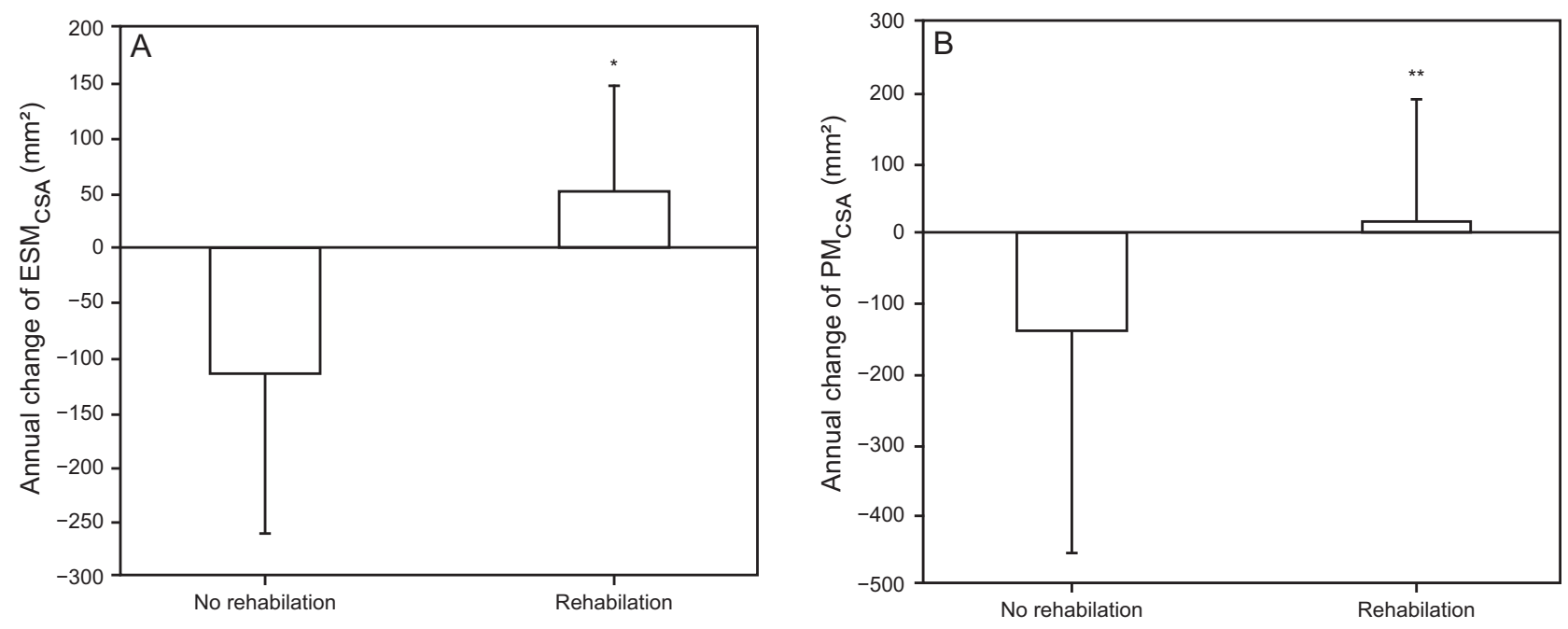

Fig. 2. Annual changes in the cross-sectional area of $(A)$ the erector spinae muscles $\left(E S M_{C S A}\right)$ and $(B)$ the pectoralis muscles $\left(P M_{C S A}\right)$ in subjects with COPD. Rehabilitation group $(n=39)$ : subjects who participated in the out-patient pulmonary rehabilitation program. No rehabilitation group $(n=39)$ : subjects did not participate in the pulmonary rehabilitation program. $E_{C S} M_{C S}$ and $P_{C S A}$ declined in the nonrehabilitation group over time and increased in the rehabilitation group. Data are mean \pm SD. ${ }^{*} P<.001$ and ${ }^{* \star} P=.02$.

Table 2. Linear Regression for Annual Changes in $\mathrm{ESM}_{\mathrm{CSA}}$ and $\mathrm{PM}_{\mathrm{CSA}}$ Using Study Groups (With or Without PR) and Baseline Values as Explanatory Variables

\begin{tabular}{|c|c|c|c|}
\hline Factors & $P$ & Factors & $P$ \\
\hline PR & $<.001$ & PR & .02 \\
\hline Baseline $\mathrm{ESM}_{\mathrm{CSA}}$ & .35 & Baseline $\mathrm{PM}_{\mathrm{CSA}}$ & $<.001$ \\
\hline \multicolumn{4}{|c|}{$\begin{array}{l}\mathrm{ESM}_{\mathrm{CSA}}=\text { cross-sectional area of erector spinae muscles } \\
\mathrm{PM}_{\mathrm{CSA}}=\text { cross-sectional area of pectoralis muscles } \\
\mathrm{PR}=\text { pulmonary rehabilitation }\end{array}$} \\
\hline
\end{tabular}

In summary, in terms of clinical background, other than PR, only triple therapy affected annual changes in $\mathrm{ESM}_{\mathrm{CSA}}$.

\section{Correlation Between Clinical Parameters and Muscle CSA}

$\mathrm{ESM}_{\mathrm{CSA}}$ at the first CT scan (baseline) was moderately and positively correlated with $\mathrm{BMI}, 6 \mathrm{MWD}$, and $\mathrm{PM}_{\mathrm{CSA}}$; a weak positive correlation was observed with inspiratory capacity; and a weak negative correlation was evident with residual volume (Table 3 ). $\mathrm{PM}_{\mathrm{CSA}}$ at baseline was moderately and positively correlated with BMI; there was a weak positive correlation with percent of predicted $\mathrm{FEV}_{1}$; and weak negative correlations were observed with residual volume and low-attenuation area percentage.

The annual changes in $\mathrm{ESM}_{\mathrm{CSA}}$ were weakly and positively correlated with mMRC dyspnea scale and COPD exacerbations during the period between the 2 CT scans; a moderate positive correlation was observed with annual changes in $\mathrm{PM}_{\mathrm{CSA}}$; and a weak negative correlation existed with the Charlson comorbidity index (Table 4).

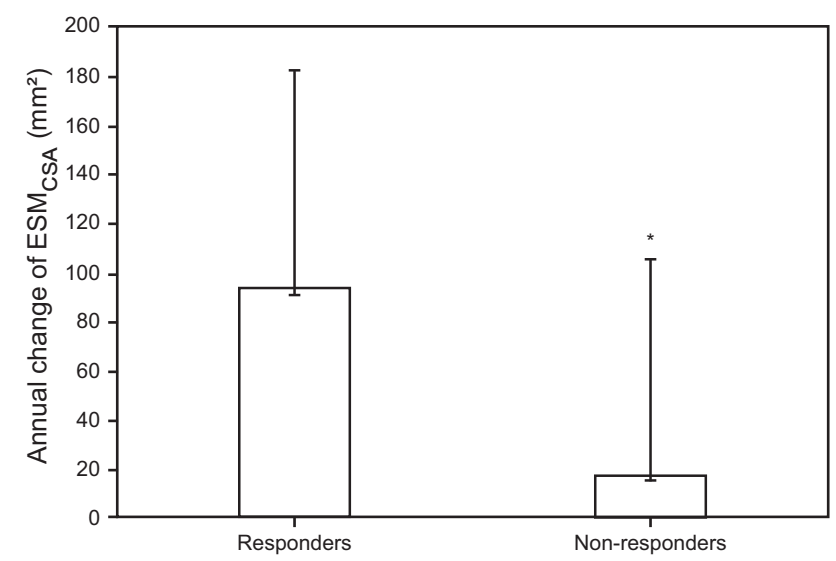

Fig. 3. Annual changes in the cross-sectional area of the erector spinae muscles $\left(E_{C S} M_{C S A}\right)$ in subjects with COPD who participated in the out-patient pulmonary rehabilitation program. Responders $(n=$ 17): subjects in whom the 6MWD increased more than the minimum clinically important difference $(30 \mathrm{~m})$ after the rehabilitation program. Nonresponders $(n=22)$ : subjects in whom the 6MWD did not increase. The annual changes in ESM $_{\text {CSA }}$ were significantly greater in responders compared with nonresponders. Data are shown as mean \pm SD. ${ }^{*} P<.001$. $6 \mathrm{MWD}=6$-min walk distance.

We performed multiple regression analysis of the annual changes in ESM $_{\mathrm{CSA}}$ and determined that PR alone was an independent variable (Table 5).

\section{Discussion}

Our results indicate that $\mathrm{ESM}_{\mathrm{CSA}}$ and $\mathrm{PM}_{\mathrm{CSA}}$ decreased year by year, and the annual changes of $\mathrm{ESM}_{\mathrm{CSA}}$ and $\mathrm{PM}_{\mathrm{CSA}}$ were different between the PR group and the nonrehabilitation group, in favor of the PR group. This is the first 
Table 3. Correlation Coefficients for $\mathrm{ESM}_{\mathrm{CSA}}$ and $\mathrm{PM}_{\mathrm{CSA}}$ at the Baseline CT Scan*

\begin{tabular}{|c|c|c|c|c|c|c|}
\hline & \multicolumn{3}{|c|}{$\mathrm{ESM}_{\mathrm{CSA}}$} & \multicolumn{3}{|c|}{$\mathrm{PM}_{\mathrm{CSA}}$} \\
\hline & Correlation Coefficient & $n$ & $P$ & Correlation Coefficient & $n$ & $P$ \\
\hline Age & -0.02 & 78 & .89 & -0.02 & 76 & .89 \\
\hline Smoking pack-years & -0.15 & 78 & .19 & 0.06 & 76 & .58 \\
\hline Body mass index, $\mathrm{kg} / \mathrm{m}^{2}$ & 0.45 & 78 & $<.001$ & 0.53 & 76 & $<.001$ \\
\hline mMRC dyspnea scale & -0.04 & 78 & .75 & -0.19 & 76 & .10 \\
\hline $\mathrm{FEV}_{1}, \%$ predicted & 0.22 & 78 & .054 & 0.24 & 76 & .033 \\
\hline $\mathrm{FVC}, \%$ predicted & 0.07 & 78 & .54 & -0.02 & 76 & .89 \\
\hline Inspiratory capacity & 0.31 & 49 & .033 & 0.28 & 76 & .055 \\
\hline Residual volume & -0.29 & 49 & .046 & -0.39 & 49 & $<.001$ \\
\hline Total lung capacity & 0.03 & 49 & .85 & -0.16 & 49 & .27 \\
\hline $\mathrm{D}_{\mathrm{LCO}}$ & 0.09 & 47 & .53 & 0.28 & 47 & .055 \\
\hline LAA $\%$ & -0.14 & 53 & .30 & -0.38 & 53 & $<.001$ \\
\hline Past COPD exacerbations & -0.09 & 78 & .44 & -0.02 & 76 & .85 \\
\hline Exacerbation(s) in period between $2 \mathrm{CT}$ scans & -0.02 & 78 & .84 & 0.06 & 76 & 60 \\
\hline Charlson comorbidity index & -0.08 & 78 & .51 & 0.05 & 76 & .65 \\
\hline COTE index & 0.10 & 78 & .40 & 0.20 & 76 & .08 \\
\hline $6 \mathrm{MWD}$ at baseline & 0.42 & 39 & $<.01$ & 0.31 & 37 & .060 \\
\hline $\mathrm{ESM}_{\mathrm{CSA}}$ & No data & No data & No data & 0.46 & 76 & $<.001$ \\
\hline $\mathrm{PM}_{\mathrm{CSA}}$ & 0.46 & 76 & $<.001$ & No data & No data & No data \\
\hline $\begin{array}{l}\text { *Spearman's correlation coefficient. } \\
\text { ESM }_{\mathrm{CSA}}=\text { cross-sectional area of erector spinae muscles } \\
\mathrm{PM}_{\mathrm{CSA}}=\text { cross-sectional area of pectoralis muscles } \\
\mathrm{CT}=\text { computed tomography } \\
\mathrm{mMRC}=\text { modified Medical Research Council } \\
\mathrm{D}_{\mathrm{LCO}}=\text { diffusing capacity of the lung for carbon monoxide } \\
\mathrm{LAA} \%=\text { percentage of the lung field occupied by low-attenu } \\
\text { COTE = COPD-specific comorbidity test } \\
6 \mathrm{MWD}=6 \text {-min walk distance }\end{array}$ & area & & & & & \\
\hline
\end{tabular}

study to report the effect of PR on the annual changes in ESMs, which are major trunk muscles. Skeletal muscle mass is an independent predictor of mortality and frailty. ${ }^{1,29}$ Exercise training alone or when combined with other treatments have favorable effects on muscle mass and function. ${ }^{13}$ However, there are no reports on the effect of PR on trunk muscle mass in subjects with COPD. A recent study reported that $\mathrm{ESM}_{\mathrm{CSA}}$ is the strongest predictor of mortality in subjects with COPD and declines year by year. ${ }^{10}$ The CSA of ESMs has also been reported to predict mortality after liver transplants and vascular surgery. ${ }^{30,31}$ The health trajectory of subjects with COPD may be improved as a result of a $\mathrm{PR}$ program that maintains $\mathrm{ESM}_{\mathrm{CSA}}$. A recent report showed that $\mathrm{PR}$ after hospitalization improved survival in subjects with COPD. ${ }^{32}$ The mechanism by which a usual PR program can improve $\mathrm{ESM}_{\mathrm{CSA}}$ remains unclear. However, reports indicate that PR for subjects with COPD improves balancing ability, ${ }^{33-35}$ which suggests that trunk muscle improvement may be implicated. Usual PR programs that include endurance training may be able to improve trunk muscles similarly to a more specific trunk flexor rehabilitation program. ${ }^{36}$

$\mathrm{ESM}_{\mathrm{CSA}}$ and $\mathrm{PM}_{\mathrm{CSA}}$ declined in some subjects even after completing the PR program. The magnitude of response to exercise training in COPD is highly variable, with some subjects achieving little or no benefit in terms of strengthening of the lower limb muscles. ${ }^{37}$ The lack of response to exercise training may relate to the inability to tolerate sufficient intensity or duration of training, or to poor adherence to the training intervention. ${ }^{37} \mathrm{We}$ measured the CSA of muscles before and after the PR program; however, because this was a retrospective study, the measurements were performed several months after the PR program in some subjects, and the CT scans were performed regardless of the PR. Therefore, the effect of the PR program might have diminished by the time measurements were recorded for some subjects.

Triple therapy (ICS/LABA/LAMA) had a favorable effect on the annual change in $\mathrm{ESM}_{\mathrm{CSA}}$, although the effect was not significant based on multiple regression analysis. Triple therapy was prescribed for subjects with COPD and a concomitant asthmatic component or frequent COPD exacerbations. ${ }^{16}$ In other words, triple therapy was prescribed for subjects who had more severe disease and symptoms. We reasoned that the annual decline in $\mathrm{ESM}_{\mathrm{CSA}}$ was greater in subjects with severe COPD complicated by frequent exacerbations, ${ }^{10}$ but the annual change in $\mathrm{ESM}_{\mathrm{CSA}}$ was not correlated with the presence of asthma-COPD 
Table 4. Correlation Coefficients for Annual Changes in $\mathrm{ESM}_{\mathrm{CSA}}$ and $\mathrm{PM}_{\mathrm{CSA}}{ }^{*}$

\begin{tabular}{|c|c|c|c|c|c|c|}
\hline & \multicolumn{3}{|c|}{$\mathrm{ESM}_{\mathrm{CSA}}$} & \multicolumn{3}{|c|}{$\mathrm{PM}_{\mathrm{CSA}}$} \\
\hline & Correlation Coefficient & $n$ & $P$ & Correlation Coefficient & $n$ & $P$ \\
\hline Age & -0.04 & 78 & .71 & -0.10 & 76 & .41 \\
\hline Smoking, pack-years & 0.02 & 78 & .90 & 0.11 & 76 & .37 \\
\hline Body mass index, $\mathrm{kg} / \mathrm{m}^{2}$ & -0.12 & 78 & .28 & -0.09 & 76 & .44 \\
\hline mMRC dyspnea scale & 0.22 & 78 & .049 & 0.10 & 76 & .41 \\
\hline $\mathrm{FEV}_{1}, \%$ predicted & -0.06 & 78 & .62 & -0.02 & 76 & .88 \\
\hline $\mathrm{FVC}, \%$ predicted & 0.03 & 78 & .81 & 0.06 & 76 & .60 \\
\hline Inspiratory capacity & 0.10 & 49 & .50 & -0.06 & 49 & .67 \\
\hline Residual volume & 0.17 & 49 & .25 & 0.08 & 49 & .57 \\
\hline Total lung capacity & 0.18 & 49 & .22 & -0.02 & 49 & .88 \\
\hline $\mathrm{D}_{\mathrm{LCO}}$ & 0.01 & 47 & .98 & 0.11 & 47 & .45 \\
\hline LAA $\%$ & -0.01 & 53 & .93 & -0.03 & 53 & .82 \\
\hline Past exacerbations & 0.21 & 78 & .060 & 0.09 & 76 & .46 \\
\hline Exacerbation(s) in period between $2 \mathrm{CT}$ scans & 0.27 & 78 & .02 & 0.12 & 76 & .30 \\
\hline Charlson comorbidity index & -0.24 & 78 & .032 & -0.14 & 76 & .21 \\
\hline COTE index & -0.15 & 78 & .19 & -0.17 & 76 & .15 \\
\hline 6MWD at baseline & -0.07 & 39 & .69 & -0.12 & 37 & .48 \\
\hline $\mathrm{ESM}_{\mathrm{CSA}}$ & No data & No data & No data & 0.41 & 76 & $<.001$ \\
\hline $\mathrm{PM}_{\mathrm{CSA}}$ & 0.41 & 76 & $<.001$ & No data & No data & No data \\
\hline Interval between $2 \mathrm{CT}$ scans & 0.16 & 76 & .16 & 0.07 & 76 & .55 \\
\hline $\begin{array}{l}\text { *Spearman's correlation coefficient. } \\
\text { ESM }_{\mathrm{CSA}}=\text { cross-sectional area of erector spinae muscles } \\
\mathrm{PM}_{\mathrm{CSA}}=\text { cross-sectional area of pectoralis muscles } \\
\mathrm{CT}=\text { computed tomography } \\
\text { mMRC = modified Medical Research Council } \\
\mathrm{D}_{\mathrm{LCO}}=\text { diffusing capacity of the lung for carbon monoxide } \\
\text { LAA\% } \% \text { percentage of the lung field occupied by low-attenua } \\
\text { COTE = COPD-specific comorbidity test } \\
6 \mathrm{MWD}=6 \text {-min walk distance }\end{array}$ & area & & & & & \\
\hline
\end{tabular}

Table 5. Least-Squares Regression Mode to Annual Changes in $\mathrm{ESM}_{\mathrm{CSA}}$

\begin{tabular}{lc}
\hline \hline \multicolumn{1}{c}{ Factors } & $P$ \\
\hline Pulmonary rehabilitation & $<.001$ \\
Triple therapy & .24 \\
Charlson comorbidity index & .28 \\
Past COPD exacerbations & .45 \\
Exacerbation(s) in period between 2 CT scans & .20 \\
Asthma-COPD overlap & .44 \\
LTOT & .08 \\
GOLD stages & .39 \\
mMRC dyspnea scale & .14 \\
& \\
\hline ESM & \\
Triple therapy $=$ cross-sectional area of erector spinae muscles & \\
roid & $\beta_{2}$ agonist/long-acting muscarinic antagonist/inhaled corticoste- \\
CT $=$ computed tomography & \\
LTOT $=$ long-term oxygen therapy & \\
GOLD $=$ Global Initiative for Chronic Obstructive Lung Disease \\
mMRC $=$ modified Medical Research Council
\end{tabular}

overlap or the number of exacerbations. Recent randomized trials have reported the superior effects of triple therapy on pulmonary function, quality of life score, and all-cause mortality compared with LAMA alone, LAMA/LABA, or
LABA/ICS. ${ }^{38,39}$ The superiority of triple therapy over single- or double-agent therapy may affect the annual change in $\mathrm{ESM}_{\mathrm{CSA}}$; however, a randomized controlled trial will be necessary to more definitively prove or disprove this hypothesis.

$\mathrm{ESM}_{\mathrm{CSA}}$ at baseline was moderately correlated with $6 \mathrm{MWD}$, while $\mathrm{PM}_{\mathrm{CSA}}$ was weakly correlated with pulmonary function parameters such as $\mathrm{FEV}_{1}$, residual volume, and percentage of the low-attenuation area. This finding is not surprising because ESMs are important for the maintenance of normal posture during walking, and the PMs are important accessory inspiratory muscles of respiration. Because the trunk muscles, including ESMs, have an important role in stabilizing the body, maintaining posture, and controlling spinal and pelvic movements, their atrophy can increase the risk of falling and limitations of activities of daily living in elderly people ${ }^{11}$ and in those with COPD. ${ }^{33}$ However, these correlations were mostly weak. Muscle CSA does not directly reflect the strength of a particular muscle because no muscle works in isolation, rather groups of muscles are generally recruited to work together. The annual change in $\mathrm{ESM}_{\mathrm{CSA}}$ was weakly and negatively correlated with the Charlson comorbidity index. In this 


\section{Pulmonary Rehabilitation and ERector Spinae Muscles}

study, we included subjects with a history of cancer or cardiovascular disease; therefore, the Charlson comorbidity index was higher than for previous reports in which such patients were excluded. ${ }^{9,10}$ Comorbidities may accelerate a decline in $\mathrm{ESM}_{\mathrm{CSA}}$. Against all expectations, COPD exacerbations during the period between the $2 \mathrm{CT}$ scans were weakly and positively correlated with the annual change in ESM $_{\text {CSA }}$. This result may be caused by the more frequent COPD exacerbations in the PR group compared with the nonrehabilitation group (Table 1).

There are several methods to evaluate muscle mass. Specifically, these include bioelectrical impedance analysis, dual-energy radiography absorptiometry, magnetic resonance imaging (MRI), and B-mode ultrasound. These methods are widely used to quantify both total and local skeletal muscle mass. Most reports of $\mathrm{ESM}_{\mathrm{CSA}}$ are based on CT scans or MRIs. ${ }^{9,10,27,30,31,40-43}$ Several studies have reported a moderate correlation between $\mathrm{ESM}_{\mathrm{CSA}}$ and isometric muscle strength using $\mathrm{CT}^{40,43}$ or MRI. ${ }^{42}$ The downside of CT scans is exposure to radiation, while MRIs are costly in terms of time and money. Chest CT scans are often used in Japan to diagnose lung disease, assess changes in emphysematous COPD, diagnose interstitial pneumonia, and for the early detection of lung cancer in the elderly because chest MRI remains inaccessible for the majority of subjects with COPD. Therefore, we used existing CT images to evaluate muscle mass without adding to radiation exposure. Ultrasound imaging may be useful for measuring CSA whenever CT scans are performed infrequently. ${ }^{44} \mathrm{We}$ could not measure muscle mass in healthy control subjects because of the nature of this retrospective study. Tanimura et $\mathrm{al}^{9}$ reported $\mathrm{ESM}_{\mathrm{CSA}}$ in subjects without respiratory disease who were nonsmoking controls. $\mathrm{ESM}_{\mathrm{CSA}}$ in control subjects $\left(3,920 \pm 698 \mathrm{~mm}^{2}\right)$ was greater than that in the subjects with COPD in this study. Trunk stabilization muscles are categorized as deep or superficial. ${ }^{45}$ ESMs are categorized as superficial muscles because they do not directly attach to vertebrae and stabilization is limited to pressurized spinal segments. The deep trunk muscles consist of the transversus abdominis, multifidus, quadratus lumborum, and rotatores muscles, which attach to individual lumbar vertebrae and provide control and rigidity for spinal segments. ${ }^{45}$ There are no reports pertaining to the stabilizing role of deep trunk muscles on the health trajectory of patients with COPD, and more research is needed to elucidate this functionality.

There are some limitations of our study. It is possible that it was underpowered, given the relatively small number of subjects. The retrospective study design included subjects with clinical backgrounds that were quite different in the rehabilitation and nonrehabilitation groups. Severe dyspnea symptoms (per mMRC) and severe disease (GOLD III-IV) were more prevalent in the rehabilitation group than in the nonrehabilitation group. The Charlson comorbidity index was higher in the nonrehabilitation group than the rehabilitation group. Symptomatic subjects with severe disease might have been referred for PR, and comorbidities could have interfered with their attendance at sessions during the PR program. Although these background differences may have affected the results, associated factors were excluded in the multiple regression analysis. The interval between the $2 \mathrm{CT}$ scans also varied, and these differences might have influenced the results. We did not assess muscle areas using multi-slice CT to measure muscle volume. CSA was analyzed via manual shading of a specific muscle area, as done in previous studies. ${ }^{910,27}$ A standard method for measuring $\mathrm{ESM}_{\mathrm{CSA}}$ has yet to be established. Automated programs to measure $\mathrm{ESM}_{\mathrm{CSA}}$ are necessary to allow more objective and precise analysis. Lastly, there were some missing data, and we were unable to analyze low-attenuation area percentage and $\mathrm{D}_{\mathrm{LCO}}$ in some subjects; these missing data may have affected the study results.

\section{Conclusions}

$\mathrm{ESM}_{\mathrm{CSA}}$ and $\mathrm{PM}_{\mathrm{CSA}}$ declined year by year in subjects with COPD, although it increased in subjects in the pulmonary rehabilitation group, suggesting that a pulmonary rehabilitation program may improve the mass of these muscles.

\section{REFERENCES}

1. Maltais F, Decramer M, Casaburi R, Barreiro E, Burelle Y, Debigaré $\mathrm{R}$, et al. An official American Thoracic Society/European Respiratory Society statement: update on limb muscle dysfunction in chronic obstructive pulmonary disease. Am J Respir Crit Care Med 2014;189(9): e15-e62.

2. Jones SE, Maddocks M, Kon SS, Canavan JL, Nolan CM, Clark AL, et al. Sarcopenia in COPD: prevalence, clinical correlates and response to pulmonary rehabilitation. Thorax 2015;70(3):213-218.

3. Limpawattana $P$, Inthasuwan $P$, Putraveephong S, Boonsawat W, Theerakulpisut D, Sawanyawisuth K. Sarcopenia in chronic obstructive pulmonary disease: a study of prevalence and associated factors in the Southeast Asian population. Chron Respir Dis 2018;15(3):250257.

4. Celli BR, Cote CG, Marin JM, Casanova C, Montes De Oca M, Mendez RA, et al. The body-mass index, airflow obstruction, dyspnea, and exercise capacity index in chronic obstructive pulmonary disease. N Engl J Med 2004;350(10):1005-1012.

5. Marquis K, Debigaré R, Lacasse Y, LeBlanc P, Jobin J, Carrier G, Maltais F. Midthigh muscle cross-sectional area is a better predictor of mortality than body mass index in patients with chronic obstructive pulmonary disease. Am J Respir Crit Care Med 2002;166(6):809-813.

6. Koo H-K, Park J-H, Park HK, Jung H, Lee S-S. Conflicting role of sarcopenia and obesity in male patients with chronic obstructive pulmonary disease: Korean National Health and Nutrition Examination Survey. PLoS ONE 2014;9(10):e110448.

7. McDonald M-LN, Diaz AA, Ross JC, San Jose ER, Zhou L, Regan EA, et al. Quantitative computed tomography measures of pectoralis muscle area and disease severity in chronic obstructive pulmonary disease: a cross-sectional study. Annals Ats 2014;11(3):326-334. 


\section{Pulmonary Rehabilitation and ERector Spinae Muscles}

8. Gayan-Ramirez G, Decramer M. The respiratory muscles. In: Fishman's Pulmonary Diseases and Disorders. New York: McGrawHill Companies; 2015.

9. Tanimura K, Sato S, Fuseya Y, Hasegawa K, Uemasu K, Sato A, et al. Quantitative assessment of erector spinae muscles in patients with chronic obstructive pulmonary disease: novel chest computed tomography-derived index for prognosis. Ann Am Thorac Soc 2016;13 (3):334-341

10. Tanimura K, Sato S, Sato A, Tanabe N, Hasegawa K, Uemasu K, et al. Accelerated loss of antigravity muscles is associated with mortality in patients with COPD. Respiration 2020;99(4):298-306.

11. Ikezoe T, Mori N, Nakamura M, Ichihashi N. Effects of age and inactivity due to prolonged bed rest on atrophy of trunk muscles. Eur J Appl Physiol 2012;112(1):43-48.

12. Smith MD, Chang AT, Hodges PW. Balance recovery is compromised and trunk muscle activity is increased in chronic obstructive pulmonary disease. Gait Posture 2016;43:101-107.

13. De Brandt J, Spruit MA, Hansen D, Franssen FM, Derave W, Sillen MJ, Burtin C. Changes in lower limb muscle function and muscle mass following exercise-based interventions in patients with chronic obstructive pulmonary disease: a review of the English-language literature. Chron Respir Dis 2018;15(2):182-219.

14. Higashimoto Y, Yamagata T, Maeda K, Honda N, Sano A, Nishiyama $\mathrm{O}$, et al. Influence of comorbidities on the efficacy of pulmonary rehabilitation in patients with chronic obstructive pulmonary disease. Geriatr Gerontol Int 2016;16(8):934-941.

15. Alison JA, McKeough ZJ, Johnston K, McNamara RJ, Spencer LM, Jenkins SC, et al. Australian and New Zealand Pulmonary Rehabilitation Guidelines. Respirology 2017;22(4):800-819.

16. Global Initiative for Chronic Obstructive Lung Disease (GOLD). Global Strategy for the Diagnosis, Management and prevention of Chronic Obstructive Pulmonary Disease. GOLD Report 2020. Available at: https://goldcopd.org/gold-reports. Accessed January 20, 2020 .

17. Minoguchi H, Shibuya M, Miyagawa T, Kokubu F, Yamada M, Tanaka $\mathrm{H}$, et al. Cross-over comparison between respiratory muscle stretch gymnastics and inspiratory muscle training. Intern Med 2002;41(10):805812

18. Kaneko H, Shiranita S, Horie J, Hayashi S. Reduced chest and abdominal wall mobility and their relationship to lung function, respiratory muscle strength, and exercise tolerance in subjects with COPD. Respir Care 2016;61(11):1472-1480.

19. Divo M, Cote C, de Torres JP, Casanova C, Marin JM, Pinto-Plata V, et al. Comorbidities and risk of mortality in patients with chronic obstructive pulmonary disease. Am J Respir Crit Care Med 2012;186 (2): $155-161$

20. Charlson ME, Pompei P, Ales KL, MacKenzie CR. A new method of classifying prognostic comorbidity in longitudinal studies: development and validation. J Chronic Dis 1987;40(5):373-383.

21. Miller MR, Hankinson J, Brusasco V, Burgos F, Casaburi R, Coates A, et al. Standardisation of spirometry. Eur Respir J 2005;26(2):319338

22. Macintyre N, Crapo RO, Viegi G, Johnson DC, van der Grinten CP, Brusasco V, et al. Standardisation of the single-breath determination of carbon monoxide uptake in the lung. Eur Respir J 2005;26(4):720735 .

23. Kubota M, Kobayashi H, Quanjer PH, Omori H, Tatsumi K, Kanazawa M, Clinical Pulmonary Functions Committee of the Japanese Respiratory Society. Reference values for spirometry, including vital capacity, in Japanese adults calculated with the LMS method and compared with previous values. Respir Investig 2014;52(4):242250 .

24. Hanamoto S, Ohsuji T, Tsuyuguchi I, Kawabata S, Kimura K. Prediction formulas for pulmonary function tests expressed in linear and exponential form for healthy Japanese adults. Nihon Kyobu Shikkan Gakkai Zasshi 1992;30(12):2051-2060.

25. Laboratories A. ATS statement: guidelines for the six-minute walk test. Am J Respir Crit Care Med 2002;166(1):111-117.

26. Polkey MI, Spruit MA, Edwards LD, Watkins ML, Pinto-Plata V, Vestbo J, et al. Six-minute-walk test in chronic obstructive pulmonary disease: minimal clinically important difference for death or hospitalization. Am J Respir Crit Care Med 2013;187(4):382-386.

27. Taka C, Hayashi R, Shimokawa K, Tokui K, Okazawa S, Kambara K, et al. SIRT1 and FOXO1 mRNA expression in PBMC correlates to physical activity in COPD patients. Int J Chron Obstruct Pulmon Dis 2017; 12:3237-3244

28. Schober P, Boer C, Schwarte LA. Correlation coefficients: appropriate use and interpretation. Anesth Analg 2018;126(5):1763-1768.

29. Schols AM, Broekhuizen R, Weling-Scheepers CA, Wouters EF. Body composition and mortality in chronic obstructive pulmonary disease. Am J Clin Nutr 2005;82(1):53-59.

30. Lee CS, Cron DC, Terjimanian MN, Canvasser LD, Mazurek AA, Vonfoerster E, et al. Dorsal muscle group area and surgical outcomes in liver transplantation. Clin Transplant 2014;28(10):1092-1098.

31. Olson SL, Panthofer AM, Harris DJ, Jordan WD, Farber MA, Cambria RP, Matsumura J. CT-derived pre-treatment thoracic sarcopenia is associated with late mortality after thoracic endovascular aortic repair. Ann Vasc Surg 2020;66:171-178.

32. Lindenauer PK, Stefan MS, Pekow PS, Mazor KM, Priya A, Spitzer $\mathrm{KA}$, et al. Association between initiation of pulmonary rehabilitation after hospitalization for COPD and 1-year survival among medicare beneficiaries. JAMA 2020;323(18):1813-1823.

33. Hakamy A, Bolton CE, McKeever TM. The effect of pulmonary rehabilitation on mortality, balance, and risk of fall in stable patients with chronic obstructive pulmonary disease. Chron Respir Dis 2017;14 (1):54-62

34. Marques A, Jácome C, Cruz J, Gabriel R, Figueiredo D. Effects of a pulmonary rehabilitation program with balance training on patients with COPD. J Cardiopulm Rehabil Prev 2015;35(2):154158.

35. Beauchamp MK, O'Hoski S, Goldstein RS, Brooks D. Effect of pulmonary rehabilitation on balance in persons with chronic obstructive pulmonary disease. Arch Phys Med Rehabil 2010;91 (9):1460-1465

36. Hides JA, Lambrecht G, Richardson CA, Stanton WR, Armbrecht G, Pruett $\mathrm{C}$, et al. The effects of rehabilitation on the muscles of the trunk following prolonged bed rest. Eur Spine J 2011;20(5):808-818.

37. Ribeiro F, Thériault ME, Debigaré R, Maltais F. Should all patients with COPD be exercise trained? J Appl Physiol (1985) 2013;114 (9):1300-1308.

38. Rabe KF, Martinez FJ, Ferguson GT, Wang C, Singh D, Wedzicha JA, et al. Triple inhaled therapy at two glucocorticoid doses in moderate-to-very-severe COPD. N Engl J Med 2020;383(1):35-48.

39. Lipson DA, Crim C, Criner GJ, Day NC, Dransfield MT, Halpin DMG, et al. Reduction in all-cause mortality with fluticasone furoate/umeclidinium/vilanterol in patients with chronic obstructive pulmonary disease. Am J Respir Crit Care Med 2020;201(12):15081516.

40. Keller A, Johansen JG, Hellesnes J, Brox JI. Predictors of isokinetic back muscle strength in patients with low back pain. Spine (Phila Pa 1976) 1999;24(3):275-280.

41. Keller A, Gunderson R, Reikeras O, Brox JI. Reliability of computed tomography measurements of paraspinal muscle cross-sectional area and density in patients with chronic low back pain. Spine (Phila $\mathrm{Pa}$ 1976) 2003;28(13):1455-1460.

42. Schlaeger S, Inhuber S, Rohrmeier A, Dieckmeyer M, Freitag F, Klupp E, et al. Association of paraspinal muscle water-fat MRI-based 


\section{Pulmonary Rehabilitation and ERector Spinae Muscles}

measurements with isometric strength measurements. Eur Radiol 2019;29(2):599-608.

43. Peltonen JE, Taimela S, Erkintalo M, Salminen JJ, Oksanen A, Kujala UM. Back extensor and psoas muscle cross-sectional area, prior physical training, and trunk muscle strength? A longitudinal study in adolescent girls. European J Appl Physiol 1997;77(1-2):66-71.
44. Tanaka NI, Ogawa M, Yoshiko A, Akima H. Validity of extendedfield-of-view ultrasound imaging to evaluate quantity and quality of trunk skeletal muscles. Ultrasound Med Biol 2021;47(3):376-385.

45. Kim S, Shim J, Kim S, Namkoong S, Kim H. The effect of superficial trunk muscle exercise and deep trunk muscle exercise on the foot pressure of healthy adults. J Phys Ther Sci 2015;27(3):711-713. 